Case Report

\title{
IM MUNOCOM PROM ISED STATUS A CAUSE OF OPPORTUNISTIC INTESTINAL INFECTION LEADING TO GRAM NEGATIVE SEPSIS
}

\author{
Rekha Rai ${ }^{1}$, Vimal Kumar Karnaker ${ }^{1}$, Krishnaprasad M. S $^{2}$, Ganesh H.R. ${ }^{3}$ \\ ${ }^{1}$ Associate Professor, Department of M icrobiology, K.S. Hegde M edical Academy, \\ ${ }^{2}$ Professor \& HOD Department of M icrobiology, K.S. Hegde M edical Academy \\ ${ }^{3}$ Lecturer, Department of M icrobiology, K.S. Hegde M edical Academy \\ Correspondence: \\ Rekha Rai \\ Associate Professor, Department of Microbiology, K.S. Hegde Medical Academy, Deralakatte, \\ M angalore - 575018. M obile No : 9480366683 E-mail : rairekharai@ rediffmail.com
}

\begin{abstract}
:
Gram negative sepsis and intestinal opportunistic infections including Cryptosporidium, Isospora, Cyclospora, Microsporidia, S.stercoralis and Candida albicans are increasingly becoming prevalent in acquired immunodeficiency syndrome (AIDS) patients. These infections are clinically important primarily because many of these have the potential for serious and even lethal complications in immunosuppressed patients. Here, we are reporting a patient with Gram-negative sepsis, who was found to be co-infected with three of these opportunistic pathogens. She was also found to be positive for human immunodeficiency virus (HIV) antibodies. To our knowledge, this has been reported once previously, and serves as a reminder to actively exclude S.stercoralisinfection in immunocompromised individuals presenting with bacteraemia.
\end{abstract}

Introduction Strongyloides stercoralis is an intestinal nematode of humans. It has a worldwide geographical distribution but is endemic in the tropics and the subtropical regions of the world. It is estimated that tens of millions of persons are infected worldwide, although no precise estimate is available. Strongyloidiasis in an immunocompetent host is an indolent disease, but in an immunocompromised host the overwhelming accelerated autoinfection cycle can potentially lead to life threatening illness with multi organ failure due to massive larval invasion known as hyper infective syndrome ${ }^{[1]}$. The hyperinfective state is associated with massive invasion of the gastrointestinal and respiratory systems and may result in widespread dissemination into other body organs or invasive strongyloidiasis.

\section{Case report}

A thirty five year old lady with unknown HIV status, was admitted in the medicine department of K.S.Hegde Medical Academy, Mangalore, with complaints of loose stools of 4-5 episodes per day, weight loss and low grade fever on and off for more than three months duration. She gave history of recent aggravation of symptoms, with high fever and chills for 2 days. Blood and stool samples of the patient received by the microbiology department were subjected to standard diagnostic microbiological examination.

Two of the three blood cultures revealed the presence of E. coli which was identified by standard biochemical reactions. The stool sample was concentrated by formolether concentration technique. A wet mount preparation revealed numerous larvae of Strongyloides stercoralis and moderate number of yeast like budding cells. Gram smear revealed moderate number of gram positive yeast like budding cells with pseudohyphae. Z-N stained smear did not reveal any acid fast bacilli. A smear stained by modified Z-N staining method revealed a large number of round pink cysts of Cryptosporidium parvum measuring 4-6 $\mu \mathrm{m}$ in diameter. However, gastric aspirate and sputum were found negative for larvae of $\mathrm{S}$. stercoralis. 
The stool sample was also inoculated on the plates of MacConkey agar, nutrient agar, and XLD. No pathogenic bacteria were isolated. Thus, the role of bacteria which may cause chronic diarrhea, were ruled out. However, culture on SDA revealed colonies of Candida species which was subjected to confirmatory tests and identified as Candida albicans. She was also found to be positive for human immunodeficiency virus (HIV) antibodies.

\section{Discussion}

Although most infected individuals are asymptomatic, Strongyloides stercoralis is capable of transforming into a fulminant fatal illness under certain conditions that are associated with an immunocompromised host such as patients on steroid therapy, those infected with human $T$ cell lymphotropic virus-1 (HTLV-1) and Human immunodeficiency virus (HIV). ${ }^{(2)}$ The isolation of Cryptosporidium in stools of HIV-infected patients from different developing countries yielded prevalence rates of $6 \%$ to $94 \%$ and that of $C$. albicans was $7.6 \%$ to $39.1 \%$. ${ }^{(3)}$ Strongyloides stercoralis causes heavy infection in AIDS patients with prevalence of about $2.5 \%$. Co-infections with Cryptosporidium and $\mathrm{S}$. stercoralis have been reported from AIDS patients. ${ }^{(4)}$ Strongyloides stercoralis is an important human parasitic infection primarily because of its potential for serious and even lethal disease in immunosuppressed patients. In the present case, Strongyloidiasis might be responsible for gram negative sepsis as intestinal flora attached to the larvae, during invasion, may also migrate throughout the body ${ }^{[5]}$. To our knowledge, gram negative bacterial sepsis in an immunocompromised patient associated with gastrointestinal Strongyloides stercoralis, has been reported once previously and serves as a reminder to actively exclude $S$. stercoralis infection in immunocompromised individuals presenting with bacteraemia $^{[2] .}$

Intestinal coccidial infection with Cryptosporidium, Cyclospora, Isospora and M icrosporidia are increasingly becoming prevalent in AIDS. Intestinal infection with Cryptosporidium is self limiting in immunocompetent individuals but leads to persistent diarrhea in advanced stage of AIDS. Yeast in stool specimen is due to transient or commensal growth in GIT. However in immunocompromised individuals it may lead to invasive disease thus proving to be a fatal opportunistic pathogen. ${ }^{(3,4)}$

To conclude, we wish to emphasize that, patients with multiple opportunistic infections, especially Strongyloidiasis, are at a high risk of developing fatal gram negative sepsis- particularly when the patient is immunocompromised. Hence, early diagnosis and treatment of parasitic infections will help in improving the quality of life in AIDS patients.

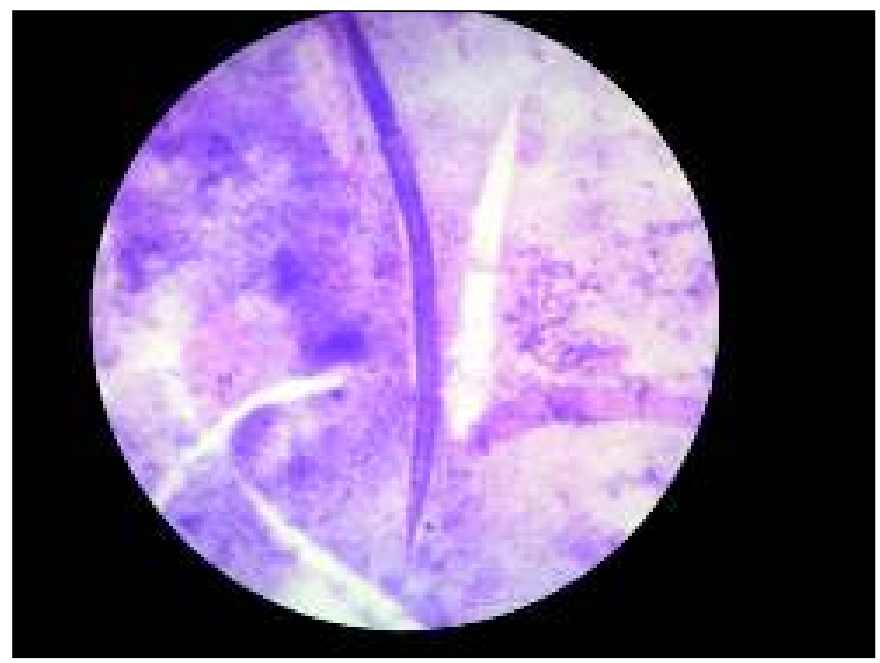

Fig 1: Larvae of Strongyloides stercoralis

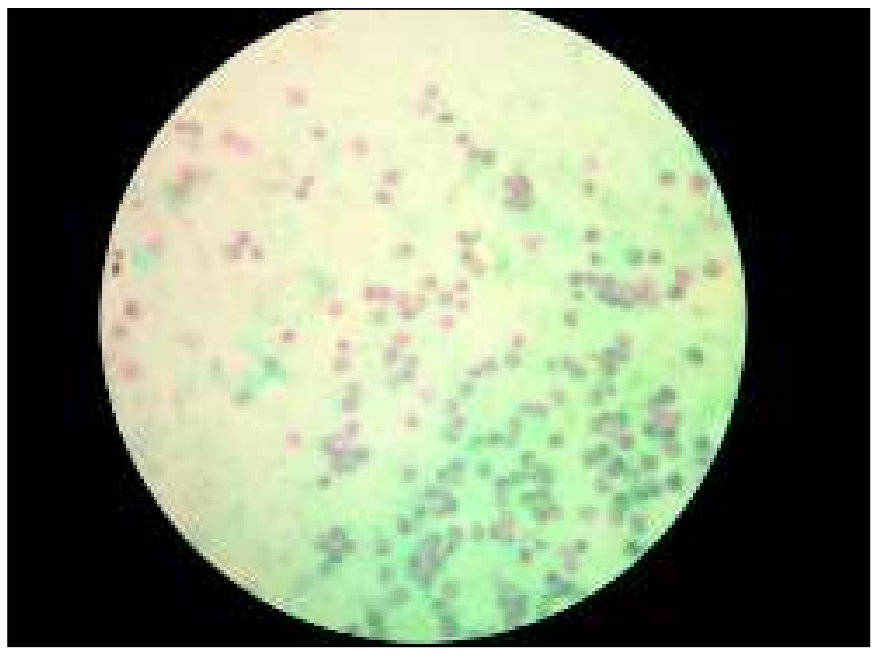

Fig 2: Cysts of Cryptosporidium parvum 


\section{References:}

1. Feitosa G, Bandeira AC, Sampaio DP, Badaró R, Brites C. High prevalence of Giardiasis and Stronglyloidiasis among HIV-infected patients in Bahia, Brazil. BrazJ Infect Dis 2001; 5:339-344.

2. Fasih N, Irfan S, Sheikh U, Beg MS. A fatal case of gram negative bacterial sepsis associated with disseminated strongyloidiasis in an immunocompromised patient. J Pak M ed Assoc 2008; 58: 91-92.

3. Rossit AR, De Almeida MT, Nogueira CA, Oliveira JG, Barbosa DM, M oscardini AC. et al. Bacterial, yeast, parasitic, and viral enteropathogens in HIV-infected children from Sao Paulo State, Southeastern Brazil. Diagn Microbiol Infect Dis 2007; 57:59-66.

4. Shah UV, Purohit BC, Chandralekha D, Mapara MH. Coinfection with Cryptosporidium, Isospora and S.stercoralis in a patient with AIDS- A case report. Indian J Med M icrobiol 2003; 21:137-8.

5. Salluh JI, Bozza FA, Pinto TS, Toscano L, Weller PF, Soares M. Cutaneous periumbilical purpura in disseminated strongyloidiasis in cancer patients, a pathognomonic feature of potentially lethal disease? BrazJ Infect Dis 2005; 9:419-24. 